\title{
«CARTAPACIOS DE VERBOS» LOS MANUSCRITOS DE LITERATURA PROPIA DE LA COMPAÑIIA DE JESÚS
}

POR

\author{
Ma Dolores García Gómez \\ Universidad de Alicante
}

\section{RESUMEN}

El documento inventarial de la Librería Chica del Colegio Máximo de Alcalá de Henares, realizado tras la expulsión de la Compañía de Jesús por Carlos III en 1767, constituye un rico ejemplo del valor que el ejercicio literario tenía entre los individuos propios de la religión jesuita. Sirve como indicativo del uso de los valores bibliográficos de las bibliotecas de la Compañía de Jesús, pero también del criterio con que se calificaron estos documentos en los registros de la expulsión.

PALABRAS ClAVE: Inventarios, Compañía de Jesús, manuscritos, bibliotecas, expulsión jesuitas, Colegio Máximo Alcalá de Henares, Carlos III.

\section{«CARTAPACIOS DE VERBOS» MANUSCRIPTS, LITERATURE OF THE SOCIETY OF JESUS}

\begin{abstract}
The document inventarial of Small Library of the Colegio Máximo de Alcalá de Henares, made after the expulsion of the Jesuits by Charles III in 1767, is a rich example of the value that was literary exercise among individuals Jesuit's own religion. It serves as an indication of the use of library bibliographic values of the Society of Jesus, but also the criteria by which these documents were described in the records of the expulsion.
\end{abstract}

KEY WORDS: Inventories, Society of Jesus, manuscripts, librarys, expulsion Jesuit, Colegio Máximo Alcala de Henares, Carlos III.

Recibido/Received 30-04-2009

Aceptado/Accepted 13-01-2012 
Cartapacios de Verbos. Con este nombre designaban, ${ }^{1}$ en el Colegio Máximo de Alcalá de Henares, la literatura generada por los padres de la Compañía de Jesús, los regulares antiguos ${ }^{2}$ ejercicios literarios que podían ser glosa y comentario de las obras de sus bibliotecas, o la obra propia, que servían, en casos, como manuales para el ejercicio de su doctrina. Con ese mismo nombre lo informaron los encargados del reconocimiento de las librerías en el registro que llevaron a cabo tras la expulsión, inventariados como localizados en los Aposentos y Librería Chica del colegio complutense, en el apartado de los manuscritos varios ${ }^{3}$ y que detallan como encuadernados en diferentes papeles y formatos.

Especifican que, reconocidos esos «cartapacios» como manuales, ...que así llamaban los Regulares antiguos, extractando para su uso algunos tratados manuscritos o impresos, y que se han puesto entre los manuscritos morales por ser de esta naturaleza la mayor parte de sus contenidos..., tenían la encuadernación en mal estado, expresando su queja ante el deterioro en que muchos de ellos se encontraban, con mucha putrefacción, y a detallar la descripción de muchos de ellos, manchados del cuévano, suciedad que les obligaba a un detenido expurgo y limpieza, labor que les lleva a autonominarse como cloacarios. Por ese servicio de limpieza, añadido al de su cometido inventarial, reclamaron la comprensión por los posibles errores, de los que anticipada y reiteradamente piden disculpa, en el cometido de un trabajo de tan precarias condiciones. ${ }^{4}$

Es sabido el desconocimiento que se tiene acerca del volumen de la documentación que el expolio de las temporalidades dejó arrinconada en los archivos de la nación, donde, en lo que no se ha mermado, continúa, ${ }^{5}$ y que constituyó en su momento el principal objeto de atención, de obsesión, ante la declaración de

${ }^{1}$ Los futuros y deseados estudios podrán decir si era nombre dado al ejercicio literario jesuita propio o solo corresponde ese título a los así llamados en el colegio complutense.

${ }^{2}$ Con este nombre eran llamados los jesuitas anteriores a la extinción y supresión, tras su vuelta en 1815, pero, en este caso, parece nombre dado por los comisionados, como referencia al ejercicio de jesuitas distantes en el tiempo, en relación con el antiguo material que estaban catalogando.

${ }^{3}$ Real Academia Historia (RAH), 9/ 2643. «Índice de los manuscritos hallados en los Aposentos, Librería chica y otros lugares del Colegio de Alcalá. de Henares: ordenado por los encargados de su reconocimiento y formación que suscriben». 11 de agosto de 1768.

${ }^{4}$ Ibídem ...Finalmente, como aunque hemos procurado que este volumen parezca en una forma conveniente con aquella decencia que nuestra situación permite, todavía reconocemos en el bastantes faltas, «quas aut incuria findit aut humana parum cavit natura,» es preciso interesar la bondad de nuestros lectores para que se compadezcan de que no hayamos podido ofrecer obra tan culta como corresponde al supremo tribunal a quien se consagra.

${ }^{5}$ Conviene reconocer cómo, en algunas sedes señeras de la misma Compañía, y como principal y primero, en la Orden, el del Colegio de Loyola y su archivo, esa documentación y su catálogo, llevado a cabo desde la misma institución en 1737, se mantuvo hasta el momento de la expulsión, según el inventario del escribano copia y ampliación de aquel, casi treinta años después. En, Fernández Arrillaga, I.

Hispania Sacra, LXV

131, enero-junio 2013, 161-180, ISSN: 0018-215-X, doi: 10.3989/hs.2013.006 
su contenido, como doctrina peligrosa. Entre esta documentación, tantas veces catalogada con el nombre genérico de libros por su encuadernación y formato, está igualmente sin identificar la literatura generada por la propia Compañía, por sus maestros y estudiosos, y que como la económica y administrativa, no ha recibido la atención que merece su análisis. ${ }^{6}$ El extraordinario volumen de este tipo de literatura, aun considerando la desaparecida, pone de manifiesto lo fielmente que se siguió la preceptiva de la Ratio respecto al ejercicio literario y a su conservación: Procure que se guarde lo dispuesto sobre el anotar en un libro lo que públicamente se presenta o escribe en el colegio o fuera de él por los nuestros, a saber diálogos, versos y cosas semejantes, una vez confiada la selección al Prefecto o a otros peritos en la materia.?

Los recientes y sugestivos estudios de las «librerías» o bibliotecas del Colegio Máximo de Alcalá de Henares, o Colegio de la Expectación — son poco significativas las referencias a la de la pequeña fundación de Jesús del Monte-, que, bajo distintos enfoques, han llevado a cabo Miguel Alonso, Santos Aramburu, Torres Santo Domingo y García-Monge Carretero, ${ }^{8}$ desvelan buena parte de las particularidades a que forzaron su acomodo, circunstancias de las que no serían ajenas el pertenecer a la universidad alcalaina, de conflictiva evolución. La dificultad de acomodación de aquel fondo documental de literatura propia al patrimonio bibliográfico jesuítico, ${ }^{9}$ puede verse incrementado en el Colegio Máximo, al estar doblemente implicada en la especial configuración de la sede universitaria complutense, por la particular idiosincrasia de las estructuras colegiales-universitarias de aquella población, muy repartida en sus funciones. A las circunstancias que rodearon la reubicación de las bibliotecas jesuíticas, tras la expulsión, a la dificultad de su inventario por la reconocida complejidad y dispersión de la propia estructura de los colegios jesuíticos, se tuvieron que añadir,

1996. «El Archivo de Loyola en tiempos de la expulsión y las aportaciones de los jesuitas llegados de Italia».

Revista de Historia Moderna, 15: 137-145.

${ }^{6}$ Mateu Ivars, J. 1998. «Manuscritos de la Compañía de Jesús en la Biblioteca General de la Universitat de Barcelona»

Una Historia Aplicada, Universidad de Barcelona. Constituye una excepción elogiable la catalogación de los manuscritos de la Compañía de la Biblioteca General de la Universidad de Barcelona, entre los fondos inventariales de la Serie de 2.030 manuscritos procedentes de los monasterios y conventos de la Ciudad Condal.

${ }^{7}$ Ratio atque Institutio Studiorm Societatis Iesu. 1599. «Reglas de Rector». 16.

${ }^{8}$ García Monge Carretero, M. I. 2004. «Inventarios de las bibliotecas de Jesuitas en la colección Biblioteca de Cortes de la Real Academia de la Historia»; y Miguel Alonso, A., Santos Aramburu, A., Torres Santo Domingo, M., en La memoria de los libros. Estudios sobre la historia del escrito y de la lectura en Europa y América.2004, 207-227, en ed. Pedro Cátedra - M. L. López Vidriero. Instituto de Historia del Libro y la Lectura, T. II, Salamanca.

${ }^{9}$ García Gómez, Ma D. 2010. Testigos de la memoria. Los inventarios de la Compañía de Jesús en la expulsión de 1767. 
en el caso del Colegio Máximo, las complejas circunstancias de la institución universitaria alcalaína, sin un centro único, complejidad que no impidió finalmente el acomodo de los libros de la Biblioteca General en la actual Biblioteca Complutense. ${ }^{10}$

\section{EL LEGADO MANUSCRITO DEL COLEGIO MÁXIMO DE ALCALÁ DE HENARES}

El legado manuscrito que nos ocupa es inevitable referente de la importancia de la biblioteca del Colegio Máximo de Alcalá importancia que conlleva el desarrollo del colegio jesuita, ${ }^{11}$ ligado a la preeminencia de la sede universitaria alcalaína, importancia iniciada desde su establecimiento, ${ }^{12}$ a la que no sería ajena la intención de Ignacio de Loyola de vincularse a aquella institución con una fundación destacada, tras su paso por ella como estudiante, y más tarde como su huésped, en la fundación de Antezana.

Se acometió con prontitud la ejecución del inventario del fondo manuscrito y el bibliográfico, ${ }^{13}$ aunque, a pesar de las buenas razones acerca de su cumplimiento, su resolución, iniciada en 1769, se dilató hasta el 30 de junio de 1770 , fecha en que la da por concluida el comisionado Francisco Ignacio de Moradillo, encargado de la tasación e índice, que inventaría, por un lado, la de la enorme masa documental del archivo del Colegio, ${ }^{14} \mathrm{y}$ por otra los manuscritos

${ }^{10}$ Miguel Alonso, A. 2004. «Nuevos datos para la historia de la biblioteca de la Universidad Complutense. La librería del Colegio Máximo de Alcalá de la Compañía de Jesús»: 462-468. La memoria de los libros. Estudios sobre la historia del escrito y de la lectura en Europa y América, Instituto de Historia del Libro y la Lectura, T. II, Salamanca, Ed. Pedro Cátedra - M. L. López Vidriero. Hubo intención en la expulsión de que los libros de la rica biblioteca jesuita de Alcalá se unieran a los de los otros colegios de su peculiar y dispersa sede universitaria, para formar una biblioteca única, aunque hubo interferencias y retrasos en aquella adjudicación, finalmente decidida en el propio colegio de la Compañía, y con el reconocimiento de un número de libros de cerca de diecisiete mil.

${ }^{11}$ Algunos manuscritos del AHPTSI informan de los primeros pasos: Cristóbal de Castro, Historia del Colegio Complutense de la Compañía de Jesús hasta 1600. Ms. C-207 (1578 bis); Alfonso de Ezquerra, Historia del Colegio Complutense de la Compañía de Jesús. 1600-1634. Ms. C-207; Joaquín de Extremera, Expulsión y ocupación de sus temporalidades. Original. 1771. Ms. C-209 bis. En el AHN en el «Indice General de los libros que se han hallado en el Colegio que fue de los regulares de la Compañía de Jesús de Alcalá de Henares». 1768 (Letras H-R). Sección Códices / 129 B.

${ }^{12}$ Burrieza Sánchez, J., 2007, p. 69, n. 44, en «Carta del P. Francisco de Estrada a Ignacio de Loyola», MHSI, Epist. Mixtae, III, Burgos, 1 de diciembre 1553, pondera la excelencia del colegio alcalaino, ... «No se que al presente la Compañía tenga mejor casa en España, si no es la de Alcalá».

${ }^{13}$ Los dos inventarios, el del archivo y de los manuscritos se encuentran en la actualidad en la RAH, Cortes, 2643-2644.

${ }^{14}$ RAH, Cortes, 9/2644. «Descripción del Archivo del Colegio, que fue de los Regulares de la Compañía, en la ciudad de Alcalá, hecha por D. Xavier de Yzuriaga y Francisco Ignacio Moradillo». En 6 de marzo de 1768 .

Hispania Sacra, LXV

131, enero-junio 2013, 161-180, ISSN: 0018-215-X, doi: 10.3989/hs.2013.006 
localizados en los Aposentos y Librería chica,${ }^{15}$ que se ordenan en 16 divisiones temáticas y dos índices alfabéticos de los autores que volcaron en sus comentarios obras impresas de autores reconocidos, pero igualmente, la obra original y manuscrita de un buen número de ellos. Ninguno de estos inventarios, el del archivo, o el llamado de la Librería chica, incluye lista alguna de los libros impresos.

La parte correspondiente a la documentación archivística, los llamados papeles, como especificamos en los datos correspondientes al colegio, constituyen una rica exposición de todo tipo de documentación relativa a la administración colegial u documentos referentes al desarrollo institucional del colegio, con el añadido que se especifica sobre las ruidosas controversias de Indias, estudios sobre Papebroquio de los PP. Poza, Tirso, a más de algunas Biblias antiguas y algunos códices griegos y arábigos, otros sobre los Evangelios, y las de la noticia de ... un volumen de siete varas de largo en que esta escrita la genealogía de la Virgen María, hacia 1346; un Libro de Job, de 1423, el Sínodo de Valladolid, de 1322, o ...los originales de la Vida del Cardenal Ximenez de Cisneros de Alvar Gómez, etc.... Reciben estas piezas la consideración de valiosas en el comentario del comisionado que las relata, aunque no detalla las razones de esa valoración, hecho que permitiría acercar el grado de instrucción de aquellos gestores, describiendo, sólo de forma global, valores de su formato, apreciaciones de los temas de que trataban: ... singulares por sus contenidos, originales por estar escritas en membranas, no puedo dejar de hacer mención de ellas sin perder de vista la brevedad con que V. A. me manda proceder... Finalmente la decisión de su destino estuvo decidida en algo más de seis meses después de su expropiación a los jesuitas —en 10 de noviembre de1767-,${ }^{16}$ así como la decisión de que pasasen a formar parte de los fondos de la universidad alcalaína.

Se enviaron ambos inventarios, el del archivo y el de los manuscritos generados por los padres del colegio, junto con los papeles y objetos inventariados, a Madrid, al Colegio Imperial, donde fueron depositados. Quedó en Alcalá la biblioteca de libros impresos, y su inventario. ${ }^{17}$ En lo concerniente al archivo, llevaron a cabo el primer recuento ${ }^{18}$ Javier Fermín de Izurriaga y Francisco

${ }^{15}$ RAH, Cortes. 9/2643. «Índice de los manuscritos hallados en los Aposentos, Librería Chica y otros lugares del Colegio de Alcalá de Henares, ordenado por los encargados de su reconocimiento y formación, que suscriben». En 11 de agosto de 1768.

${ }^{16}$ Diego Pareja, L. M., La expulsión de los jesuitas de Alcalá de Henares en 1767 y vicisitudes de sus propiedades hasta su regreso en 1827. Alcalá Ensayo, 16.

${ }^{17}$ Miguel Alonso, A., 2004, p. 471: Informa estar organizado el inventario por autores, con formula diferente al de otros inventarios, y especificando el origen de su localización, con las iniciales de L. G. (Librería Grande)

${ }^{18}$ RAH 9/2644. Descripción del Archivo del Colegio, que fue de los Regulares de la Compañía, en la ciudad de Alcalá, hecha por los Señores DD. Fermín de Yzuriaga y Francisco Ignacio de Moradillo. 
Hernández de Moradillo, ${ }^{19}$ y es con fecha de 11 de agosto de 1768 cuando lo firman como concluido, con el escribano Ramón Vicente Merodio ante Juez de Ocupación de las Temporalidades y corregidor de Alcalá, Antonio Fernández Soler.

A pesar de su planificada reubicación, el legado bibliográfico sufrió la forzada dispersión a que lo avocaba su misma importancia y volumen, aunque esa dispersión y olvido ha incidido particularmente en los documentos inventariales, de intrínseca caducidad temporal, frente a la del libro, de una realidad y función mantenida. Cabe citar el catálogo existente de la Biblioteca General, o Librería Grande, con fecha de 13 de junio de $1759,{ }^{20}$ catálogo que tuvo repetidas y sucesivas ampliaciones, la principal la llevada a cabo unos meses después de la expulsión, cuando se programa la entrega de su contenido a la Universidad de Alcalá, en noviembre de $1767,{ }^{21}$ o el llevado a cabo en 1776, al hacer efectiva la entrega, ${ }^{22}$ igualmente el del recuento en su estancia como biblioteca de la universidad, que se mantiene hasta 1797, y un último, en 1799, antes de llevar los libros al Colegio de San Ildefonso.

En cuanto al inventario de las obras manuscritas que ahora describimos, desde el Prólogo del Indice los mismos comisionados ya advierten del valor de algunos ejemplares, ${ }^{23}$ en las obras de originales de reconocidas autoridades de filosofía o teología, donde los PP. Millan García, Juan Manuel, Gabriel Vázquez y Antonio Rubio, apuntaron sus diversas especies morales y teológicas extractando tal vez.

\footnotetext{
6 de Marzo 1768.

${ }^{19}$ RAH 9/2644. Descripción del Archivo del Colegio, que fue de los Regulares de la Compañía, en la ciudad de Alcalá, hecha por los Señores DD. Fermín de Yzuriaga y Francisco Ignacio de Moradillo. 6 de Marzo 1768.

${ }^{20}$ Katagraphe librorum huius biliothecae, con el recuento de 7640 libros.

${ }^{21}$ Index alphabeticus librorum per authorum cognomina, con cifra de 4594 entradas.

${ }^{22}$ Memoria de los libros que de las librerías y aposentos que fue de los Regulares expulsos de la Compañía extinguida de la ciudad de Alcalá de Henares. 1776. Esta memoria incluía los libros de la Librería Grande, los de la Librería Chica, los de los aposentos de los Padres del Colegio, los de los aposentos de los teologos, los de los aposentos de huéspedes, los del despensero, los de la botica y los contenidos en la biblioteca de un pequeña casa llamada Jesús del Monte.

${ }^{23} \mathrm{RAH}$ 9/2643, describen el método de intervención los comisionados que lo llevan a efecto...En los Manuscritos varios hay algunos tomos en que estan guardados diferentes papeles que se hubieran repartido a sus diferentes lugares a no impedirlo esta accidental colocación... Hemos tenido por suficiente diligencia inventariarlas por vía de Indice alfabético de sus autores sin dejar por eso de dar una noticia competente de las que no son puramente escolástica: en el pues se han incluido todas ya esten encuadernadas ya en cuadernos suelto, acomodando en la palabra varios no solo las anonimas, sino las descabaladas, de que por serlo no hemos podido descubrir su autor y también los apuntamientos, papeles y cuadernos sueltos de los aposentos. Los tratados o materias diferentes de un mismo autor se han colocado siguiendo el orden que lleva Santo Tomás en las partes de su Suma, cuanto ha permitido la irrupción de la Escolástica en esta facultad el siglo pasado y el cuidado con que hemos procedido expresando los duplicados y advirtiendo los escritos originales
}

Hispania Sacra, LXV

131, enero-junio 2013, 161-180, ISSN: 0018-215-X, doi: 10.3989/hs.2013.006 
para su uso algunos tratados manuscritos o impresos, con las materias philosophicas y theologicas de las escuelas, especialmente las que se leyeron desde el principio del siglo XVII, son una especie de manuscrito en el que apenas hay otra cosa que saber que el tratado o punto sobre el que silogizan y porfian los que escriben y atendiendo principalmente a que han entendido y entienden dos profesores theologos en su lectura con el cargo de anotar lo que puede contener censurable o contra el comun sentir, recordando también la necesidad surgida de apoyo profesoral para la comprensión de su contenido, en el que, dado el tono con que se expone, no parecen encontrar ninguna «peligrosidad». ${ }^{24}$

Se recoge en una única relación inventarial el destino de ese corpus bibliográfico manuscrito, aunque no se especifica los provenientes de la Librería Grande, ${ }^{25}$ que acogen buena parte de los del archivo y la administración colegial, junto con la descripción detallada de los de la Librería Chica, ${ }^{26}$ antigua y primera localización libraria del Colegio Máximo, que pudo alternar, en momentos su nominación con la de Librería Vieja, en atención a su primitiva función y establecimiento, una vez relegada del uso y categoría de la principal, aunque esa constitución de depósito, ajeno a las renovaciones bibliográficas que recibiera la Librería Grande, la convierte en el rico registro inventarial que ahora nos ocupa. Esa librería vieja, engrosada y constituida a lo largo del tiempo, cobijó los papeles de archivo, las obras desusadas, o desfasadas, y pudo ser el posible recinto de las obras retiradas bajo censura, ${ }^{27}$ pero, especialmente, se constituyó según constatamos, en el reducto de la producción literaria manuscrita del ejercicio colegial, y constituye, según detalla el inventario, una excepcional colección de las obras propias de creación o comentario de los padres de la Compañía de Alcalá. El epígrafe en que está especificado el contenido de cada uno de los temas con que fueron catalogados todos los documentos archivados, hace, que, en ocasiones, se pueda interpretar como obra impresa algunas de las entradas referidas a obra manuscrita, cuando además se trata de autores de reconocida importancia en el panorama literario de su momento $-\mathrm{y}$ en otros colegios que

${ }^{24}$... las materias philosophicas y theologicas de las escuelas, especialmente las que se leyeron desde el principio del siglo XVII, son una especie de manuscrito en el que apenas hay otra cosa que saber que el tratado o punto sobre el que silogizan y porfian los que escriben y atendiendo principalmente a que han entendido y entienden dos profesores theologos en su lectura con el cargo de anotar lo que puede contener censurable o contra el comun sentir.

${ }^{25}$ Descripción del Archivo del Colegio que fue de los Regulares de la Compañía, en la ciudad de Alcalá, hecha por los DD. Javier Fermin de Izuriaga y Francisco Ignacio de Moradillo. 6 de marzo de 1768 .

${ }^{26}$ Índice de los Manuscritos hallados en los aposentos, Librería Chica y otros lugares del Colegio de Alcalá de Henares, ordenado por los encargados de su reconocimiento y formación que suscriben. 11 de agosto de 1768 .

${ }^{27}$ La nota manuscrita de los comisionados que aparece entre los folios del registro, puede llevarnos a valorar el interés entre este tipo de literatura, según comentamos más adelante. 
hemos revisado pueden llegar a incluir en la descripción del manuscrito el año de la publicación del texto que glosan o reproducen-, llevando al equívoco de poder considerar, en esa apariencia, como inventario de libros impresos lo que no lo era, y titular como inventarios de bibliotecas de la Compañía de Jesús este tipo de producción literaria: ${ }^{28}$ porque esa similitud en la descripción inventarial de obra manuscrita o impresa, anda pareja en la equivalencia del uso, patente en la proximidad de uno y otro formato en los anaqueles de las estanterías, según informa un registro del Archivo Histórico Nacional, con extensión de 352 folios, inventario de la obra impresa de la biblioteca del colegio de Alcalá. ${ }^{29}$ Del contenido de esta relación de obra impresa son nulas las apreciaciones bibliográficas que se pueden deducir, dado el carácter parcial de su relación - abarca solo los autores contenidos de la $\mathrm{H}$ a la $\mathrm{R}-$, se mantienen las constantes de las bibliotecas jesuitas: autores de su propia religión, importante presencia de materia concerniente a la teología moral, y notable número de obras impresas en el siglo XVI. Algunas obras y autores de ese fondo antiguo están profusamente presentes, y sirve de ejemplo la obra de Maldonado, y sus Comentarii in quatuor evangelii de 1549, de los que hay diecinueve ejemplares, las Opera de Tomas de Kempis, con veintinueve ejemplares, los Ejercicios de san Ignacio en número de trece, las de Pedro Lombardo, con treinta y seis ejemplares. Enorme es también la presencia teológica de Marín, con mas de ciento treinta y siete ejemplares, o de Kircher, el maestro propio tan reconocidamente presente en las bibliotecas jesuitas. De una obra poco frecuente en el común de las bibliotecas, la de Mariana, según recoge el inventario aquí en número importante, especialmente la de la Historia de la Compañía o la misma Historia de España, así como la de Malebranche, en edición de 1512, de escasísima presencia. Pero no es este documento inventarial, a pesar de estar tan estrechamente vinculado a nuestra búsqueda, del que ahora queremos hacer el seguimiento.

Hemos hecho referencia conjunta expresa a la situación con que se vieron afectados los bienes bibliográficos impresos y manuscritos, para poner de manifiesto como, en la llamada Librería Chica, coexistían la obra impresa y la

\footnotetext{
${ }^{28}$ Desde la misma normativa se puede considerar la facilidad al equívoco, como se contiene en la Real Provisión de 23 de abril de 1767, en la «Instrucción de lo que se deberá observar para inventariar los libros y Papeles existentes en las Casas que han sido de los Regulares de la Compañía, en todos los Dominios de S. M.», epígrafe XVIII, ... suele acontecer que en granjas, o residencias anejas a los Colegios, hay Papeles o Libros manuales, que servían al uso de los Regulares, que por tiempo residían en ellas; y como pertenecientes a la Compañía deben añadirse al Indice de Libros de la Respectiva Casa, bajo de las Reglas que van indicadas respecto a los Aposentos, por militar iguales circunstancias...

${ }^{29}$ AHN. Códices. 1129. «Índice General de los libros que se han hallado en el Colegio de la Expectación que fue de los Regulares de la Compañía de Jesús de Alcalá de Henares, año de 1788. Letras $H$ a R»
} 
manuscrita, y que dicha situación, sugestiva en su alcance, desvela la aparición de esta «otra» literatura, de glosa o comentario, contenida entre la olvidada y relegada de los archivos de temporalidades, bajo la denominación de «papeles manuscritos», ${ }^{30}$ que declaran una situación de material didáctico, informativo, espiritual, de trascendente peso. Su vigencia, la permanencia formal de ese aprovisionamiento, no solo con los escritos de los autores del siglo XVI y XVII sino con obra de autores del mismo XVIII, demuestra la persistencia de su uso, y nos acerca a las conclusiones que tan certeramente expuso Bouza sobre la pervivencia del manuscrito, en coexistencia del impreso. ${ }^{31}$ En esa memoria de las autoridades propias, trasladadas por medio de sumulas, notas y excerpta de los libros leídos, mantuvo la Compañía de Jesús la mayor de las fidelidades, como nos recuerda el mismo Bouza que ocurre en la obra del jesuita Pedro de León, Compendio de las industrias en los ministerios de la Compañía de Jesús, de 1628, ejemplo, «tesoro documental», para Bouza, por calificar al manuscrito como vehiculo de una difusión controlada, en atención a que es más veraz ( es decir controlado) que el impreso. ${ }^{32}$

\section{Los CARTAPACIOS}

Y volviendo ya a esos llamados cartapacios, ese nombre genérico que el mismo Cervantes aplica al manuscrito de Cide Hamete que en la Ancana de Toledo vende un muchacho con la historia de Quijote - denominación todavía sin la carga estereotipada con que hoy le reconocemos al vocablo - , informa el Prólogo del orden seguido en la relación inventarial: los tratados o materias del mismo autor se colocaron en el orden que lleva Sto. Thomas de su Suma, por quanto ha permitido la irrupción de la escolástica en esta Facultad el siglo pasado.

Se realiza la descripción del contenido de esa masa documental en una Tabla, con remisión a las planas - número foliado - en que estos empiezan, y también incluyen aquellas en las que no han podido descubrir el autor, los apuntamientos, papeles y cuadernos sueltos y descabalados, ${ }^{33}$ reduciéndola a distintas

${ }^{30}$ García Gómez, Ma D., 2001, p. 138-151.

${ }^{31}$ Bouza, F., 2001., p. 19-22 y 29, 39-41.

${ }^{32}$ Ibídem, p. 58-59.

${ }^{33} \mathrm{RAH}$ Cortes $9 / 2643$. describe el sistema de ordenación de los distintos asuntos de que trataban los papeles contenidos en el archivo... La Tabla que está a continuación de este Prólogo manifiesta casi a una mirada a que clases se reducen todos los papeles de los Aposentos y Librería Chica de este Colegio y de la Casa de Jesús del Monte (aunque de esta solo vino un corto número de sermones, poesias, Cartas al ministro de ella y otras cosas de poca consideración) cuantos legajos tiene cada clase y en que plana de este Inventario empieza cada uno y aunque esta práctica excluye el método de inventariar 
clases para su ordenación, éstas en número de 18, con enumeración de los legajos correspondientes a cada clase que remite al folio en que se inicia. Se diferencian en la Tabla las primeras 15 clases con la descripción de los diversos temas de administración colegial, repartidos en 62 legajos, que atienden los papeles de gobierno y uso colegial o documentos propiamente de archivo, ${ }^{34}$ la clase XVI atiende al los manuscritos morales ${ }^{35}$ la XVII a los de materias filosóficas, ${ }^{36}$ y la XVIII a las materias teológicas, éstas os ultimas, las de manuscritos filosóficos y teológicos descritas con índice alfabético de autores. ${ }^{37}$ De esos cartapacios, contenidos en esas diferenciadas clases, la primera, o XVI, está repartida en 74 legajos; la clase XVII, tiene una extensión de 56 folios para las materias filosóficas y la clase XVIII, última, de 34 folios, para las teológicas: el índice de las materias filosóficas y el de las teológicas, con extensión de 144 folios, no lleva diferenciación de legajo. Los primeros XV apartados o clases acogen al resto de la documentación, repartidos en 62 legajos, que atienden los papeles de gobierno y uso colegial o documentos propiamente de archivo. ${ }^{38}$

seguidamente todos los papeles de cada aposento u oficina, para que siempre conste cuales eran de cada parte, según se fueron separando y trayendo a la clase se anotó en cada lugar donde fue hallado.

${ }^{34} \mathrm{RAH}$, Cortes, 9/2647. Relación de los enunciados descritos en la Tabla o Índice. Ls. 1-5, «Patronatos de P. Rector»; Ls. 5-6, «Juros, Censos y pps pertenecientes a las Santas Formas»; L. 7 «Capellanía, administración de las rentas de Librería y Aula y Fundación de las Cátedras de Prima y Visperas»; Ls. 8, 9, 10, «Congregación de la Anunciata»; L. 11, «Colegio de estudiantes pobres de san Ignacio»; Ls. 8 a 18, «Libros y cuadernos de cuenta y razón y otros papeles tocantes a hacienda e intereses» [se ocupan especialmente de los libros y razón de labranza, de los del Padre Ropero, de las cuentas de la cocina y enfermería, y también de los papeles de hacienda relativos al colegio de Alcalá, a los del Imperial, Toledo y Murcia, hallados entre los de Jesús del Monte de Alcalá y Librería Chica]; L. 19, «Bulas y disciplina interior»; L. 20 «Libros de oficio del Rector»; L. 21 «Cartas sueltas de los PP. Generales»; L. 22, «Libros de Visitas»; L. 23, «Libros de exámenes»; L. 24, «Libros Verdes»; L. 25, «Cédulas, Correspondencia de los Provinciales»; L. 26, «Cartas annuas, cartas de difuntos»; L. 27, «Cartas de los Regulares y correspondencia privada»; L. 28, «Correspondencia de los Regulares con los externos»; L. 29, «Correspondencia literaria»; L. 30, 31, «Correspondencia espiritual»; L. 32, 33, «Papeles y Libros espirituales»; L. 34, «Borradores y copias del pleito del P. Fco. Lili e Idiaquez»; L. 35, 36, «Diferentes asuntos de esta y otras universidades, lecciones de oposición, venias y gallos»; Ls. 37, 38, «Libros y Papeles de gramática, humanidad y otras poesías»; 1. 39, «Papeles extravagantes, licencias»; L. 40, «Relativos a la expulsión de Francia, al motín de Madrid, políticos y satíricos, contra el V. Palafox»; L. 41, «Sermones del apartamento del P. Rector»; Ls. 42, «97 cuadernos de pláticas de Ejercicios»; L. 43, «Colección de cuadernos»; Ls 44 a 58, «Sermones»; Ls. 59, 60, 61, «Varios manuscritos»; Ls. 61-62, «Manuscritos sobre las Congregaciones De Auxiliis». En el folio 446 especifica la Tabla estar los «Papeles de Botica».

${ }^{35} \mathrm{RAH}$, Cortes, 9/2643. Tabla de las clases y papeles que cada una tiene con remisión a las planas en que estos empiezan. Clase XVI, Manuscritos Morales. Leg. 63 a 74, Plana 270 a 304;

${ }_{36}$ Ibídem. Tabla de las clases y papeles que cada una tiene con remisión a las planas en que estos empiezan. Clase XVII. Índice Alfabético de materias Filosoficas; Planas 311 a 339;

${ }^{37}$ Ibídem. Tabla de las clases y papeles que cada una tiene con remisión a las planas en que estos empiezan. Clase XVIII, Indice Alfabético de Materias Theologicas. Planas 339. a 446.

${ }^{38} \mathrm{RAH}$, Cortes, 9/2647. Relación de los enunciados descritos en la Tabla o Índice. En el folio 446 especifica la Tabla estar los «Papeles de Botica».

Hispania Sacra, LXV

131, enero-junio 2013, 161-180, ISSN: 0018-215-X, doi: 10.3989/hs.2013.006 
Hacemos continua referencia a la extensión física de los documentos contenidos, para poner de relieve esa importancia, constatable también en el número de las obras originales manuscritas de los primeros maestros de doctrina de la Compañía, Ignacio Peinado, Francisco Vázquez, Antonio Portillo, Carlos Echevarria, Juan Marín, Francisco Pastrana, Gaspar Hurtado, Gabriel Vázquez, Antonio Rubio, Gaspar de Rivadeneira, cuyo prestigio en su tiempo los constituían en importantes bastiones de la doctrina jesuítica y de la universidad de Alcalá, en el siglo anterior al de su catalogación, el XVII.

Los enunciados de los manuscritos morales, recogidos en once legajos, resumen con exactitud cada uno de los ingentes trabajos, algunos de ellos dedicados al comentario de la Summa Moralis de santo Tomás, ${ }^{39}$ así como las conferencias de Moral tenidas desde el año de 1572 hasta 1664 presididas por los PP. Maestros Gabriel Vázquez, Luís de Torres, Antonio Rubio, Gonzalo de Albornoz, Gaspar Hurtado, o Gaspar de Rivadeneira, al Tratado sobre los Sacramentos de Suárez, y a las obra de Esparza, Azpilicueta, Soto, Victoria, Vázquez, Castro, Molina, Ripalda, y en abundantes ejemplares el comentario a la obra De matrimonio de Tomás Sánchez o la del Espíritu de perfección de Alonso Rodríguez. Constituyen un buen número los sumarios de las sesiones de los Concilios Tridentino y Toledano de año 1566.

La lectura de la relación del inventario tiene pocos alicientes significativos respecto al que ofrecería una relación impresa, especialmente en los títulos de las obras de escolástica o filosofía. Sólo algunos enunciados de los manuscritos del apartado de «morales», motiva a los comisionados a una descripción algo más prolija: en esas notas o comentarios es posible entrever la prevención y atención que debían llevar dichos responsables acerca de la búsqueda de la doctrina peligrosa, que les hace estar atentos a cualquier posible titulo, o interpretación de su contenido, censurable, como se refiere en el legajo 65, donde habían volcado sus opiniones morales los Maestros Cristóbal de Castro Diego de Sigoney, Gaspar Hurtado, Francisco Alfonso, Gabriel Vazquez, Antonio Rubio, (plana 373) [sic] Gonzalo de Albornoz, Marcelo de Aponte, Juan Perlin, Juan de Valenzuela Gaspar de Moncada, Agustin de Herrera, Juan Cortes Osorio, Pedro de Rivadeneira, resoluciones morales y respuestas a varias de las preguntas surgidas en el ejercicio de su magisterio que como Regulares de este Colegio en las Conferencias de Moral desde los años 1572 a 1664, en el que se habían

\footnotetext{
${ }^{39}$ Sirva como ejemplo de la extensión de cada uno de los enunciados el del legajo 65, un manuscrito original del P. Sancho de Pedrosa, intitulado Thesaurus Moralis, per verba ordine alphabetico digesta, consta de más de 80 cuadernos desordenados que todos hacen 827 hojas en folio, 17 en medio folio y 8 en $4^{\circ}$. Otro manuscrito en 780 hojas en $f^{o}$ encuadernado en pergamino que empieza, Lectura del $P$. Suarez de la Compañia de Jesús: de sacramentis elucidata Compluti. y acaba asi unde peccaret qui sine his secundis litteris interetur prioribus. Libreria chica.
} 
discutido acerca de si...preguntose si cuando el Rey promulga alguna ley en su corte si bastaría esta promulgación para que obligue a todo su reino, o si sería necesario que se promulgase en cada provincia; o la de ...si los predicadores evangélicos pueden reprender publicamente a los Reyes o a los Prelados eclesiásticos, y como se deben haber los príncipes reprendidos; y la que plantea el P. Ocampo para averiguar con más luz la obligación que su Magestad tiene en los 3 puntos del papel, fuera bien que como en el se ponen los inconvenientes y daños que se siguen de los adjuntos coadjutores ingresos y pensiones, se pusieran también las utilidades y provechos: y termina que mientras le durasen esos títulos le durarán también esa obligación aunque no hubiera otro en el mundo que la tuviera. Estos temas, descritos tan minuciosamente $-\mathrm{y}$ no sólo como prescribía la normativa de incluir las primeras palabras y las últimas del manuscrito-, parecen el eco del aviso ante determinadas heterodoxias que sirvieran como acusación a la Compañía de Jesús al cuestionar la autoridad real. otros temas también merecen cuidadosa atención, aunque hoy sea difícil la interpretación de asuntos aparentemente ajenos, como el descrito en el legajo 67, apartado 10, que anota una observación del P. Ripalda, si puede llegar la fortaleza a cerrar puertas al temor en todo genero de peligros. Muchos de los comentarios sobre esos manuscritos que provocaron la atención acerca de la peligrosidad de su contenido, sirven de recorrido temporal acerca de las diferentes actuaciones en las que estuvo puesta la Compañía en un punto de mira riguroso, desde su fundación, ... Un catecismo de moros, preámbulo de la conversión de los moros, y ponderase la gravedad de la materia; Acerca del cambio del justo precio de las mercadurías con el parecer de Francisco de Vitoria, Martín de Azpilicueta o Domingo de Soto, y Acerca de cómo se cambia en Flandes para las ferias de Castilla; Acerca de la instrucción para oir Missa que predicó Fr. Bartolomé de Miranda delante del Rey de Inglaterra, en 1555; o Acerca del modo de absolver a indianos ricos, sacado del Obispo de Chiapa, firmado (quiere decir aprobado) de Cano; o el Memorial que presentó a la Ciudad de Murcia el PP. Calatayud suplicando al Ayuntamiento hiciese voto de no admitir en su pueblo comedias de Farsa; la Consulta, respuesta y apuntamiento del Banco de Gremios, o la Relación de los echos, circunstancias y resoluciones que tuvo presente el señor Obispo de N. para proceder a la rebaptización condicionada de todos los bautizados por el cura $N$ en los treinta y siete años que disfrutó de su parroquia hasta que por la declaración judicial de su insuficiencia se le suspendió de oficio, en el verano de 1757-, o a los de discusión en su propia religión, especialmente los de la doctrina acerca del probabilismo - la impugnación del P. Ripalda contra Miguel Bayo-, y las diatribas que su resolución generó.

La descripción de los Manuscritos Filosóficos o Índice Alfabetico de los Autores de Materias Filosóficas, inicia un número currens que abarca 113 entradas de 39 autores, recogida en 28 folios -311 a 339-, y se continua en la descripción de los Manuscritos Theologicos o Índice Alfabético de los Autores de 
Materias Theológicas, que comprenden 640 entradas de 114 autores, a lo largo de 295 folios, cantidades de una y otra área que suman las 754 entradas de estas dos áreas, expuestas en orden alfabético. La relación la encabeza su número, seguida apellido y nombre del autor, de su pertenencia a la Compañía de Jesús, del título subrayado, el tamaño, encuadernación y número de hojas. ${ }^{40}$ Siempre figura como último dato el de la localización, que solo en contadas ocasiones remite a algún aposento, pues prácticamente toda la producción está localizada en la Librería Chica, aunque al final de las obras de una y otra área se describen las obras localizadas en las librerías personales de los aposentos del P. Rector y otros cuartos. No cabe duda, a la vista de los autores que contiene la lista, que el área más atendida en esos comentarios doctrinales eran los de la escolástica tradicional: esta prioridad podía sustentarse en la correspondencia de la actividad jesuita con la universidad, como es sabido anclada en aquel referente doctrinal de tan persistente ejercicio, que gran número de esos comentarios recogen en el análisis a la obra de Santo Tomás, y en la de otros de menor relevancia de esa disciplina. En los comentario a las obras filosóficas, prima, es casi exclusivo, el análisis de las obras aristotélicas, en cada uno de los temas de los que se ocupó el estagirita, la lógica, metafísica, física, recogidos de algunos de los autores que profundizaron en su análisis, Acosta, Hurtado, Vázquez, pero igualmente abundantes tratados sobre las disputationes, y algunos cursos filosóficos. Tanto en la descripción primera, no alfabética, de los manuscritos morales, como en la de las obras filosóficas y teológicas, tiene un amplio espacio la entrada de varios, casi siempre con la justificación, ante lo incompleto de su descripción, de estar esas obras descabaladas. El índice está redactado con letra clara, y con excepcional limpieza.

Una accidental circunstancia enriquece también la información que aporta el inventario de esta documentación manuscrita, llegada de mano del olvido por parte de los encargados o comisionados de la ejecución del inventario: en el documento archivado, en el legajo de la Real Academia de la Historia que guarda la información obtenida, y que parece, a la vista de esta evidencia, nunca llegó a ser conocida ni utilizada, hay «perdida» entre sus folios una hoja suelta, donde se comentan, después de ser expurgados, algunos epígrafes de esos primeros 62 legajos, y los comentarios a que dan lugar tienen el valor añadido de revelar el criterio que guiaba a esos comisionados para localizar e informar esa calificación de «doctrina peligrosa». La documentación de Temporalidades nos ha hecho tener siempre bien presente el afán de pesquisa, de búsqueda que guiaba a las comisiones formadas al efecto al llevar a cabo el inventario de los

${ }^{40}$ Sirva de ejemplo la primera entrada de los ms. teológicos: $N^{o} 114$. Abarca (P. Petrus) e Societ. Tractatus de justificatione; et de voluntate Dei. Un tomo en $4^{\circ}$, encuadernado en pergamino, que tiene 164 hojas. Librería Chica. 
«papeles»y los libros. Esas comisiones cumplieron con pulcritud y exigencia esa intención y ordenes, y a la vista del documento que aporta este informe del Colegio de Alcalá, pues mucho y fino tuvieron que hilar esos comisionados para encontrar motivos peligrosos en esa documentación. Este documento, que decimos olvidado o ignorado, dada su desconexión con el resto de la documentación, nos trae ante los ojos lo que en la revisión de la documentación del Colegio alcalaino encontraron como «peligrosa» aquellos comisionados. Dicha hoja, enunciada como Piezas notables en el Índice de Aposentos Y Librería Chica del Colegio de Alcalá de Henares, remite, no a piezas notables manuscritas, como su título indica, sino a las que en su consideración podían ser perceptibles de una revisión censural, como se puede apreciar con la simple lectura de sus contenidos. En un cuadro delimita los legajos en donde se encuentran las posibles desafecciones, y el número del apartado concreto dentro del legajo. No podemos dejar de transcribirlo como muestra del criterio que guió dicha selección:

Piezas notables en el Índice de Aposentos Y Librería Chica del Colegio de Alcalá de Henares.

Leg. $\mathrm{n}^{\circ}$ 13, apartado 4: Violencias del Colegio de Alcalá ante el triste estado de la Casa de Navalcarnero.

Leg. $\mathrm{n}^{\circ}$ 18, 8: Ante la no fundación de una Cátedra en el Colegio de Belmonte para la que había una dotación de la Duquesa de Nájera.

Leg. $\mathrm{n}^{\mathrm{o}} 21, \mathrm{n}^{\mathrm{o}} 2,9,12,16,19,20,21,27,33,34$ : Oposición a la doctrina de Aristóteles; Uso del chocolate y otras bebidas y relojes de cuerda; Carta en la que se expresa que aunque en Filosofía se enseñen las cuestiones y principios aunque no sean teologicos; Acerca de la enseñanza de las matemáticas y de las ciencias experimentales; Para que se estudie por medio de la Medulla de Busembaum; Carta del Provincial en 14 de octubre de 1758, José de Velasco; Colección de papeles de materia teológica del P. Cuevas, de 257 hojas en $4^{\circ}, 31$ en folio; Defensa de seis proposiciones de Santo Tomás.

Leg. $\mathrm{n}^{\circ}$ 27, 2-4: Los PP. Sigüenza y Cuenca piensan en representar al Rey contra los disparates que se estampan en la Gazeta abusando de su nombre; 4, Crítica muy del genio de los Regulares, y dize el Ministerio por medio deste libro librarse de la esclavitud del Estado eclesiastico, como en Inglaterra y una clausula que parece peligrosa: "Aquí fingimos contento, no porque lo hay, sino porque non possumus progredi, et pudor regredi.»

Leg. $n^{\circ} 28,20$ : Sobre pretensiones.

Leg. no 33, 4: Una especie de letanías para los meses de Enero, Febrero y Marzo en que se invocan a varios Regulares de la Compañía. 
Leg. $\mathrm{n}^{\circ}$ 37, 11: Razones del Padre Rubio al Consejo para tener un autor asentado en Latinidad. Reprueba un arte que se quería obligar a que se leyese en la Corona del Rey de España.

Leg. $\mathrm{n}^{\circ}$ 39, 7: Poniendo los medios para estorbar que los PP. Escolapios pusiesen casa en esta ciudad.

Leg. n ${ }^{\circ}$ 40: Expulsión de Francia.

Leg. $\mathrm{n}^{\circ}$ 46, 1: Revelación que ninguno de la Compañía muriendo en ella se había de condenar en 300 años, revelación hecha a San Francisco de Borja.

Leg. n ${ }^{\circ}$ 62: Sobre las Congregaciones De Auxiliis.

La consideración de «notables» de estos títulos enmascara la intención de delatarlos como sospechosos, que es la condición que claramente manifiesta la inclusión en esta lista, por la descripción de su título. Es de suponer que sería de difícil valoración la cantidad de informes llegados, como éstos, de los expurgos comisionales, pues, según este documento, la consideración de su peligro no se atiene a la preceptiva marcada por la orden real, sino que, y parece la causa de algunos de los hechos aquí incluidos como sospechosos, tuvieron que añadirse sobre la marcha, todos los posibles y presuntamente reprobables, a fin de evitar que apareciera una «lista negra» poco abultada que hiciera poner en duda el riguroso y cuidadoso seguimiento de las ordenes recibidas.

Queda como una muestra notable para la valoración de las bibliotecas jesuitas este inventario de la obra manuscrita del colegio de Alcalá, recogida entre los papeles y libros de las temporalidades, compuesta por sus propios individuos, cuya primera y más elemental importancia, como decíamos, deviene de la dimensión de su volumen, que permite considerarla como otra fuente de información, hasta hoy poco valorada, para la reconstrucción del ideario bibliográfico de la Compañía ${ }^{41}$ Con estas obras manuscritas - ejercicios para la reflexión, el estudio o la docencia, que en la práctica totalidad de los casos no se llegaron a imprimir-, en la singular aportación que constituye en la religión jesuítica $-\mathrm{y}$ en el resto de las ordenes religiosas práctica de conveniente y necesitada revisión en el estudio de su constituyente doctrinal-, en esos cartapacios de verbos, cuya similar y normalizada descripción respecto a las obras impresas las convierten en perverso lugar de equívocos, queda abierta su deseada identificación y revisión, ante la segura importancia del peso cultural e ideológico que aportan para la revisión de los patrones doctrinales. La prolija descripción del material literario del relevante colegio complutense, nos muestra también

${ }^{41}$ Egido, T., 1991: 203, invocaba, ya entonces, la necesidad de de una valoración de la desamortización cultural que supuso la expulsión, y especialmente la referida a los libros de las bibliotecas. 
un ejercicio escrupuloso por parte de los comisionados que lo llevaron a cabo, y sirve de contrapunto ante la supuesta ortodoxia de aquellas valoraciones, muchas veces calificada como apresurada e inexacta.

\section{ApÉNDICE DOCUMENTAL ${ }^{42}$}

«Índice de los manuscritos hallados en los Aposentos, Librería chica y otros lugares del Colegio de Alcalá. de Henares: ordenado por los encargados de su reconocimiento y formación que suscriben». 11 de agosto de 1768 .

\section{Prologo}

La reducción a clases de que da idea este inventario ha sido operación muy difícil, asi por haver muchas faltos, menudos, impertinentes, como por haber otros que constando de diversos cuadernos sueltos, cada uno destos yacia a larga distancia de sus compañeros. El acabalar estas piezas reuniendo sus partes ha sido fatigoso, por la variedad de foliaciones, numeros y llamadas, en que a cada paso nos enredabamos, intentando reducir la lectura a su primera y natural progresión. Pero aunque al cabo hemos dejado algunos manuscritos en su mismo desorden o descabalamiento, desengañados de que la ordenación de los primeros exigia más tiempo que el nuestr, y casi imposible de los segundos. El deseo de que nuestro trabajo fuese indice de la complacencia con que nos empleamos en este distinguido encargo, nos empeñó y condujo al logro de haber ordenado muchos, y sujetados a sus debidas clases los papeles más menudos y despreciables.

La tabla que esta a continuación deste Prologo manifiesta casi a una mirada a que clases se reducen todos los papeles de los aposentos y Librería Chica deste colegio y de la casa de Jesús del Monte (aunque desta solo vino un corto numero de sermones, Poesias, cartas al Ministro de ella, y otras cosas de poca consideración) quantos legajos tiene cada clase y en que plana deste inventario empieza cada uno. Y aunque esta practica excluye el metodo de inventariar seguidamente todos los papeles de cada aposento u oficina; para que siempre conste cuales eran de cada parte segun se fueron separando y trayendo a la clas, se anoto en cada uno el lugar adonde fue hallado.

En la economia de las clases se han reducido a la segunda de las prevenidas en la Circular de 29 de Julio de 1767 los pocos papeles relativos a aquel numero

\footnotetext{
${ }^{42}$ En los documentos originales citados a lo largo del trabajo, así como en el Apéndice Documental se ha respetado la ortografía original al trascribirlos.

Hispania Sacra, LXV

131, enero-junio 2013, 161-180, ISSN: 0018-215-X, doi: 10.3989/hs.2013.006
} 
o Congregación de estudiantes pobres que concurrian a este colegio a alimentarse e instruirse en la teología escolastica y Moral, con el titulo de estudiantes de San Ignaci, aunque no usaban habito diferente de los demás escolares desta universidad.

Se han separado y extractado las cartas de los Padres Generales en observancia de orden de 28 de Agosto, y siendo pocas las originales se han unido a las que insetaban los Provinciales en las suyas, para hacerselas saber a los Rectores. La correspondencia destos y la reciproca de los Regulares sobre puntos de su disciplina, la privada de los ultimos con los externos, la literaria y la espiritual: toda se ha colocado y ordenado cronológicamente, advirtiendo con brevedad lo que ha parecido notable.

Las demas Cartas pertenecientes a la Hacienda, intereses u otras materias determinadas, estan puestas después a los asuntos a que se refieren. De estas son las tocantes a los Patronatos del P. Ror y a las Administraciones del Juro y Censos de las Sttas, Formas, y de las rentas de la Librería, Aula, Congregación de la Annunciata y Colegio de San Ignacio, que tenian a su cargo diferentes Regulares por razon de sus oficios. Todas las quales y algunas otras se hallaran en sus respectivos Legajos.

En los «Manuscritos varios» hay algunos tomos en que estan guardados diferentes papeles que se hubieran repartido a sus diferentes lugares a no impedirloesta accidental colocación. Lo mismo ha sucedido con unos manuales que entre los Regulares antiguos se llamaban «cartapacios de verbos», tales son unos tomos en octavo en que los PP. Millan García, Juan Manuel, Gabriel Vázquez y Antonio Rubio apuntaron sus diversas especies morales y teológicas extractando tal vez para su uso algunos tratados manuscritos o impresos, las materias philosophicas y theologicas de las escuelas, especialmente las que se leyeron desde el principio del siglo XVII, son una especie de manuscrito en el que apenas hay otra cosa que saber que el tratado o punto sobre el que silogizan y porfian los que escriben y atendiendo principalmente a que han entendido y entienden dos profesores theologos en su lectura con el cargo de anotar lo que puede contener censurable o contra el comun sentir. Hemos tenido por suficiente diligencia inventariarlas por vía de Indice alfabético de sus autores sin dejar por eso de dar una noticia competente de las que no son puramente escolástica: en el pues se han incluido todas ya esten encuadernadas ya en cuadernos suelto, acomodando en la palabra varios no solo las anonimas, sino las descabaladas, de que por serlo no hemos podido descubrir su autor y también los apuntamientos, papeles y cuadernos sueltos de los aposentos. Los tratados o materias diferentes de un mismo autor se han colocado siguiendo el orden que lleva Santo Tomás en las partes de su Suma, cuanto ha permitido la irrupción de la Escolástica en esta facultad el siglo pasado y el cuidado con que hemos procedido expresando los duplicados y advirtiendo los escritos originales. 
...Finalmente, como aunque hemos procurado que este volumen parezca en una forma conveniente con aquella decencia que nuestra situación permite, todavía reconocemos en el bastantes faltas, «quas aut incuri fundit aut humana parum cavit natura,» es preciso interesar la bondad de nuestros lectores para que se compadezcan de que no hayamos podido ofrecer obra tan culta como corresponde al supremo tribunal a quien se consagra.

\section{TABLA DE LAS CLASES DE PAPELES Y LEGAJOS QUE CADA UNA TIENE, CON REMISIÓN A LAS PLANAS EN QUE ESTOS EMPIEZA}
Clase I Ls. 1-5: «Patronatos de P. Rector»; Ls. 5-6, «Juros, Censos y pps pertenecientes a las Santas Formas»; L. 7 «Capellanía, administración de las rentas de Librería y Aula y Fundación de las Catedras de Prima y Visperas»
Clase II Ls. 8, 9, 10, «Congregación de la Anunciata»; L. 11, «Colegio de estudiantes pobres de san Ignacio»
Clase III Ls. 8 a 18, «Libros y cuadernos de cuenta y razón y otros papeles tocantes a hacienda e intereses» [se ocupan especialmente de los libros y razón de labranza, de los del Padre Ropero, de las cuentas de la cocina y enfermería, y también de los papeles de hacienda relativos al colegio de Alcalá, a los del Imperial, Toledo y Murcia, hallados entre los de Jesús del Monte de Alcalá y Librería Chica]

Clase IV L. 19, «Bulas y disciplina interior»; L. 20 «Libros de oficio del Rector»; L. 21 «Cartas sueltas de los PP. Generales»; L. 22, «Libros de Visitas»; L. 23, «Libros de exámenes»; L. 24, «Libros Verdes»; L. 25, «Cédulas, Correspondencia de los Provinciales»; L. 26, «Cartas annuas, cartas de difuntos»; L. 27, «Cartas de los Regulares y correspondencia privada»

Clase V L. 28, «Correspondencia de los Regulares con los externos»

Clase VI L. 29, «Correspondencia literaria»

Clase VII L. 30, 31, «Correspondencia espiritual»; Papeles y Libros Espirituales

Clase VIII L. 34, «Borradores y copias del pleito del P. Fco. Lili e Idiaquez»

Clase IX L. 35, 36, «Diferentes asuntos de esta y otras universidades, lecciones de oposición, venias y gallos»

Clase $\mathbf{X} \quad$ Ls. 37, 38, «Libros y Papeles de gramática, humanidad y otras poesías»

Clase XI L. 39, «Papeles extravagantes, licencias»

Clase XII L. 40, «Relativos a la expulsión de Francia, al motín de Madrid, políticos y satíricos, contra el V. Palafox»

Clase XIII L. 41, «Sermones del apartamento del P. Rector»;: Ls. 42, «97 cuadernos de pláticas de Ejercicios»; L. 43, «Colección de cuadernos»; Ls 44 a 58, «Sermones»

Clase XIV Ls. 59, 60, 61, «Varios manuscritos»

Clase XV Ls. 61-62, «Manuscritos sobre las Congregaciones De Auxiliis» 
Clase XVI Ls. 63 a 74. «Manuscritos Morales»

Clase XVII «Indice alfabetico de las materias filosóficas;»

Clase XVIII «Indice alfabetico de las materias Teológicas.» En el folio 446 especifica la Tabla estar los «Papeles de Botica», y una nota sobre otros Papeles.

\section{BIBLIOGRAFÍA}

Batllori, M. 1968. «Conspectus Bibliographici». Archivum Historicum Societatis Iesu. XXXVII.

Martínez de la Escalera, José 1982. «Ciencias y Letras de los jesuitas en a Provincia de Aragón. 1747-67». Miscelanea Comillas XL/77: 263-325

Bouza Álvarez, Fernando J. 1992. Del escribano a la biblioteca. La civilización escrita europea en la Alta Edad Moderna (Siglos XV-XVII). Madrid: Editorial Síntesis.

Bouza Álvarez, Fernando J. 2001. Corre manuscrito. Una historia cultural del siglo de Oro. Madrid: Marcial Pons. Historia.

Burrieza Sánchez, J. 2007. Valladolid. Tierras y Caminos de Jesuitas. Presencia de la Compañía de Jesús en la provincia de Valladolid. 1545-1767. Diputación de Valladolid. Burrieza Sánchez, J. 2004. «La antigua Compañía de Jesús. Siglos XVI-XVIII)»: Los jesuitas en España y en el mundo hispánico. Teófanes Egido. (coord.) Madrid: Fundación Carolina: Centro de Estudios Hispánicos e Iberoamericanos.

Diego Pareja, L. M. 1997. La expulsión de los jesuitas de Alcalá de Henares en 1767 y vicisitudes de sus propiedades hasta su regreso en 1827. Alcalá de Henares.: Fundación Colegio del Rey.

Egido, Teófanes. 1991. «El regalismo.» Iglesia, Sociedad y estado en España Francia e Italia. (s. XVIII al XX). E. La Parra y J Pradells (dir.) Diputación Provincial de Alicante: Instituto Juan Gil Albert.

Fernández Arrillaga, Inmaculada. 1996. «El Archivo de Loyola en tiempos de la expulsión de los jesuitas llegados a Italia. Jesuitas en la España del siglo XVIII». Revista de Historia Moderna. Anales de la Universidad de Alicante. $\mathrm{N}^{\mathrm{o}}$ 15: 137-148.

García Gómez, M a D. «La biblioteca de jesuitas de Albacete en el trance de la expulsión. (1767).» Actas del I Congreso de Historia de la Iglesia en España y en el Mundo Hispánico. Vol. LII. N 105. PP. 229-258. 2000.

García Gómez, Ma D. 2000. «Los colegios de la provincia de Albacete de la Compañía de Jesús». Exposición conmemorativa. Los Caminos de la Luz. Museo Municipal de Albacete. Albacete.

García Gómez, Mª D. 2001. Memoria de unos libros. La biblioteca de los jesuitas expulsados del Colegio de Albacete. Diputación de Albacete: IEA Don Juan Manuel. 
García Gómez, Mª D. 2010. Testigos de la memoria. Los inventarios de la Compañía de Jesús en la expulsión de 1767. Publicaciones. Universidad de Alicante.

García Monge Carretero, M. I. 2004. «Inventarios de las bibliotecas de Jesuitas en la Colección Biblioteca de Cortes de la Real Academia de la Historia». La Memoria de los Libros. Estudios sobre la historia del escrito y de la lectura en Europa y América. T. II.: 207-227. Salamanca: Instituto de Historia del Libro y de la Lectura: Ed. Cátedra, P. M. - López.

Mateu Ibars, J. 1998. «Manuscritos de la Compañía de Jesús en la Biblioteca General de la Universitat de Barcelona»: Una Historia Aplicada: 154-172. Universidad de Barcelona.

Miguel Alonso, A. 2004. «Nuevos datos para la historia de la Biblioteca de la Universidad Complutense. La librería del Colegio Máximo de Alcalá de la Compañía de Jesús»: La Memoria de los Libros. Estudios sobre la historia del escrito y de la lectura en Europa y América. T. II: 459-481. Salamanca: Ed. Cátedra, P. M. - López Vidriero, M. L.

Santos Aramburu, A. y Torres Santo Domingo, M. 2004. «La Biblioteca Histórica de la Universidad Complutense: Una primera aproximación a sus procedencias.»La Memoria de ls Libros. Estudios sobre la historia del escrito y de la lectura en Europa y América. T. II. Ed. Cátedra, P. M. - López Vidriero, M. L. 